\title{
Does continuous use of inhaled corticosteroids improve outcomes in mild asthma? A double-blind randomised controlled trial
}

\author{
*Helen K Reddel, Elena G Belousova, Guy B Marks, Christine R Jenkins \\ Woolcock Institute of Medical Research and University of Sydney, Camperdown, New South Wales, Australia
}

Received 6th November 2007; revised version received 9th January 2008; accepted 20th January 2008

\begin{abstract}
Aim: To compare the effects of fluticasone and placebo on asthma control in patients with mild asthma.

Method: Adults with $\mathrm{FEV}_{1}>80 \%$ predicted and reliever use $\leq 2$ times/week were randomised to receive fluticasone $250 \mathrm{mcg} / \mathrm{day}$ or placebo double-blind for 11 months. Exacerbations were treated with four weeks' fluticasone 500 mcg/day. Primary outcomes were electronically-recorded morning PEF and $\mathrm{FEV}_{1}$, analysed by mixed model regression.

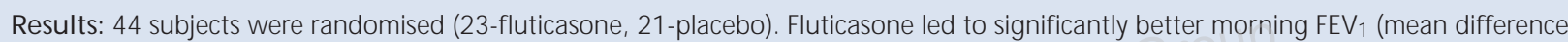
$5.4 \%$ predicted, $p<0.0001$ ), morning PEF, clinic spirometry, exhaled nitric oxide levels, and airway hyperresponsiveness, but there were no differences in reliever use, symptoms or quality of life. Fewer patients had mild exacerbations on fluticasone $(22 \%$ vs $62 \%, p=0.02)$.

Conclusion: The goals of asthma treatment include not only control of symptoms, but also prevention of future adverse outcomes such as exacerbations - which can occur even in mild asthma. This study showed that treatment with low dose inhaled corticosteroids led to significant improvements in lung function, exacerbations, and in pathophysiological predictors of future risk, even though symptoms were minimal at entry. For patients with mild asthma, discussion about treatment needs to consider not only short-term benefit, side effects and cost, but also long-term reduction of risk.

This study was completed prior to mandatory registration for clinical trials.

(c) 2008 General Practice Airways Group. All rights reserved.

HK Reddel, et al. Prim Care Resp J 2008; 17(1): 39-45.

doi:10.3132/pcrj.2008.00014
\end{abstract}

Keyw ords mild asthma, asthma pharmacotherapy, assessment of treatment response, fluticasone

\section{Introduction}

In recent years, the basis of treatment decisions in asthma has shifted from a classification of severity, to one based on disease control. Both the 2006 Global Initiative for Asthma guidelines (GINA) ${ }^{1}$ and the recently-published Expert Panel Report 3 guidelines for the USA ${ }^{2}$ advocate a stepwise treatment algorithm, based on an assessment of asthma control. The aim is to achieve well controlled asthma, which is characterised by minimal symptoms and minimal reliever use, no limitation of activity, normal (or near normal) lung function, and no exacerbations.

At present, these guidelines recommend low dose inhaled corticosteroid (ICS) treatment if a patient experiences symptoms three or more times a week, or if the forced expiratory volume in one second $\left(\mathrm{FEV}_{1}\right)$ is below $80 \%$ predicted. Several placebo-controlled studies have investigated the effect of ICS in such patients, with low dose ${ }^{3-6}$ and moderate-to-high dose ICS. ${ }^{7,8}$ There has been vigorous discussion about these studies, ${ }^{9 \cdot 16}$ with commentators reaching different conclusions about the implications for clinical practice. This suggests that consensus has not yet been achieved on the optimal treatment strategy for patients with what used to be called "mild persistent asthma".

Patients with less frequent symptoms (i.e. 2 days/week)

* Corresponding author: Associate Professor Helen Reddel, PO Box M 77 Missenden Road, Camperdown, New South Wales, Australia, NSW 2050. Tel: +61 295157026 Fax: +61295505865 E-mail: hkr@med.usyd.edu.au 
are classified in current guidelines as having "intermittent asthma," ${ }^{1,2}$ or, if they achieve this low frequency of symptoms while taking low dose ICS (Step 2 treatment), they are classified in the 2006 GINA guidelines as having "Controlled Asthma" . In clinical practice, they are often simply described as having "mild asthma". For such patients, ICS are not currently recommended, and there are very few clinical trials of low dose ICS in this population. Rytila and colleagues ${ }^{17}$ showed in a three-month single-blind placebo-controlled study that beclometasone $800 \mathrm{mcg} / \mathrm{day}$ led to improved symptom scores and blood eosinophil counts in patients with recent-onset asthma symptoms who had normal lung function, bronchodilator response and airway responsiveness. The potential target for ICS in patients with mild asthma is indicated by the finding of airway inflammation and/or airway hyperresponsiveness (AHR) despite the presence of very mild clinical features..$^{18}$ These biomarkers may act as predictors of future risk, providing additional information about asthma control over and above the information obtained from standard clinical measures. ${ }^{2}$

The present study was designed to test the hypothesis that for patients with clinically mild asthma, defined by symptoms $\leq 2$ days/week, regular treatment with low dose ICS would be more effective than regular treatment with placebo in maintaining asthma control, avoiding exacerbations, and achieving best lung function.

\section{Methods}

This was a randomised, double-blind, placebo-controlled, parallel-group, single centre study. Subjects were randomised to receive fluticasone propionate $125 \mathrm{mcg}$ or matching placebo twice-daily by metered-dose inhaler for 11 months. Use of a large-volume spacer was encouraged. Salbutamol $100 \mathrm{mcg}$ was used as-needed. In both groups, exacerbations were treated with four weeks of open-label fluticasone propionate $250 \mathrm{mcg}$ twice-daily by metered-dose inhaler, with oral corticosteroids if necessary. The study protocol was approved by the Ethics Committee of Royal Prince Alfred Hospital, and all subjects gave written informed consent. The study was completed prior to mandatory registration for clinical trials.

\section{Subjects}

Subjects were aged 18-80 years, with an established history of asthma - documented either by historical evidence of bronchodilator reversibility within the previous year (increase in $\mathrm{FEV}_{1}$ by $>180 \mathrm{mls}$ and/or $>12 \%$, or in peak expiratory flow (PEF) by $>12 \%$ ), or by confirmation by two independent physicians on a case-by-case basis that the subject had a clinical history of reversible symptoms which were consistent with asthma.

Subjects were defined as having "mild" asthma if they satisfied inclusion criteria at both Visit 1 (screening visit) and Visit 2 (randomisation visit). The inclusion criteria for mild asthma at Visit 1 were $\mathrm{FEV}_{1}>80 \%$ predicted, and use of salbutamol $\leq 2$ times/week excluding pre-exercise. Exclusion criteria at screening were: current smoking or a >20 packyear smoking history; clinically important systemic or respiratory disease; treatment with oral/systemic corticosteroids in the previous year; long-acting $\beta_{2}$-agonist treatment in the previous month; or a respiratory infection in the previous month. Subjects could be using salbutamol alone, or low dose ICS ( $\leq 250 \mathrm{mcg} /$ day fluticasone or its equivalent). Previous ICS, if used, were continued during the four-week run-in and ceased at randomisation. Subjects using moderate dose ICS $(>250-<500 \mathrm{mcg} / \mathrm{day}$ fluticasone equivalent) at Visit 1 underwent eight-week run-in on half their entry dose. No asthma medications other than asneeded salbutamol were permitted. Further inclusion criteria for mild asthma at randomisation were: $\mathrm{FEV}_{1}>90 \%$ of Visit 1 $\mathrm{FEV}_{1}$, symptoms $\leq 2$ times/week, salbutamol $\leq 2$ times/week excluding pre-exercise, and mean morning PEF $>92 \%$ best (low PEF variability, based on published ${ }^{19}$ and unpublished data). Subjects were excluded at randomisation if they had moderate airway hyperresponsiveness (provocative dose of histamine causing a $20 \%$ fall in $\mathrm{FEV}_{1}\left(\mathrm{PD}_{20}\right)<0.1 \mu \mathrm{mol}$ histamine) or excessive diurnal PEF variability (average amplitude percent mean $>15 \%$ in previous 14 days).

Randomisation was by computer-generated sequence, with a block size of six, and the randomisation code remained concealed until after analysis. Subjects were assessed at weeks 4 and 8 , then every eight weeks up to week 48 , withholding salbutamol and caffeine for six hours, and antihistamines for one week. Throughout the study, subjects carried out electronic monitoring of symptoms, medication use and spirometry (PEF and $\mathrm{FEV}_{1}$ ) twice-daily, using AM2 electronic diary spirometers (Erich Jaeger $\mathrm{GmbH}$, Hoechberg, Germany). For PEF and $\mathrm{FEV}_{1}$, the highest of three manoeuvres was analysed. Baseline observations were from the randomisation visit and the preceding 14 days' diary data.

\section{Exacerbations}

Subjects were asked to contact the investigator if they had worsening symptoms, or if PEF was $\leq 80 \%$ baseline. Mild asthma exacerbations were defined as: (a) a fall in morning PEF of $\geq 20 \%$ from baseline on $\geq 2$ of three consecutive days; and/or (b) increase in 24-hour salbutamol use by $>2$ occasions over baseline on two consecutive days; and/or (c) nocturnal asthma and/or early waking requiring salbutamol on $\geq 2$ consecutive days; and/or (d) if, in the investigator's opinion, the subject was experiencing an exacerbation. Subjects meeting these criteria were instructed to take exacerbation medication for four weeks, plus study medication, with telephone review two weeks later and clinic review two weeks after that. 
Severe exacerbations were defined by use of oral corticosteroids. Oral prednisolone $50 \mathrm{mg} /$ day was given for 7 10 days if PEF fell by $\geq 30 \%$ baseline for $\geq 2$ of three consecutive days, or at investigator discretion. Subjects were withdraw $n$ if they required prednisolone for more than four weeks, or additional ICS for more than eight weeks, or if they experienced three exacerbations.

\section{Outcome variables}

Primary outcome variables were morning PEF and morning $F V_{1}$. Secondary diary variables included symptom score, $\beta_{2}-$ agonist use, waking due to asthma, symptom-free days, and reliever-free days. Secondary clinic variables included $\mathrm{FEV}_{1}$, FVC and PEF, and Asthma-related Quality of Life (Marks ${ }^{20}$ ). Exhaled nitric oxide (NO) concentration (FeNO, expiratory flow $200 \mathrm{~mL} / \mathrm{sec}$ ) was measured offline (ThermoEnvironmental 42C analyser, Thermo-Environmental Instruments Inc, Franklin, Massachusetts), and adjusted for ambient NO. Airway responsiveness was assessed by histamine provocation test, ${ }^{21}$ with cumulative doses from 0.06-7.8 $\mu \mathrm{mol}$. Total fluticasone dose was calculated as the sum of prescribed study medication plus exacerbation medication, averaged as mcg/day.

\section{Statistical analysis (also see Appendix A at ww w.thepcrj.org)}

Spirometry sessions in which $\mathrm{FEV}_{1}$ or PEF was $>4$ standard deviations (SD) above the subject's 11-month mean (18/9583 spirometry sessions) were excluded from analysis. Reliever use was averaged over each two-week period and expressed as puffs/day. Each day was classified as symptom-free (Yes/No) and reliever-free (Yes/No) for analysis. Asthma-related quality of life data could not be normalised by transformation, and were dichotomised about the median value. Analysis was by intention to treat, for all subjects who received at least one dose of study medication. For continuous outcome variables, all post-randomisation values were compared between treatment groups using an analysis of variance in which treatment group was the main fixed effect, baseline measures were included as fixed covariates, and subjects were treated as a random effect. Mean differences (with 95\% confidence intervals [CI]) were estimated. Dichotomous variables were analysed using generalised estimating equations with a log link to estimate relative risk (with 95\% Cl). Numbers of subjects with exacerbations were compared between active and control groups by $\mathrm{Chi}$ squared test. Analyses were carried out using SAS Version 9.1 (SAS Institute Inc., Cary, NC, USA) and Analyse-It Version 1.68 (Analyse-It Software Ltd, Leeds, UK).

\section{Power calculation}

A power analysis for the primary efficacy variable (morning PEF) was performed prior to database lock, based on the number of subjects recruited and previous electronic spirometric data during well controlled asthma. ${ }^{22}$ Assuming between-subject SD for morning PEF of 80-120 L/min and intra-subject correlation coefficient in the range $0.005-0.2$, with 22 subjects in each of the two groups, and 360 daily observations per subject, the minimum detectable difference in morning PEF with $80 \%$ power was between 6 and 47 L/min.

\section{Results}

Forty-four subjects were randomised (Active - 23, Placebo 21 , see Figure 1). Fifteen subjects (34\%) were using ICS at entry (low dose - 12, moderate dose - 3). Table 1 shows baseline and demographic characteristics. There were no clinically important differences between randomisation groups, or between subjects using or not using ICS at entry (See Appendix A, online supplement, at www.thepcrj.org).

At baseline, subjects had clinical features of mild or well controlled asthma, with median salbutamol use 0.2 puffs/week (IQR 0.0-1.2), clinic $\mathrm{FEV}_{1} 99 \%$ predicted $(95 \% \mathrm{Cl}$ 94.5-103.9), and normal to mild AHR. However, FeNO was elevated $\left(>13.2 \mathrm{ppb}^{23}\right)$ in $70 \%$ of patients, with no significant difference between subjects using/not using ICS at entry $(p=0.16$, see online supplement). Retrospective classification by GINA 2006 criteria identified $57 \%$ patients with "Controlled", 39\% "Partly Controlled", and 4\% "Uncontrolled" asthma.

\section{Primary outcome variables (Table 2)}

Morning PEF was 15.9 L/min higher $(95 \% \mathrm{Cl} 12.4-19.4$, $\mathrm{p}<0.0001$ ) on active treatment compared with placebo. A similar effect was seen with morning $\mathrm{FEV}_{1}$, group difference $151 \mathrm{~mL}(114-184, \mathrm{p}<0.0001)$.

\section{Figure 1. CONSORT diagram show ing the flow of subjects through the study.}

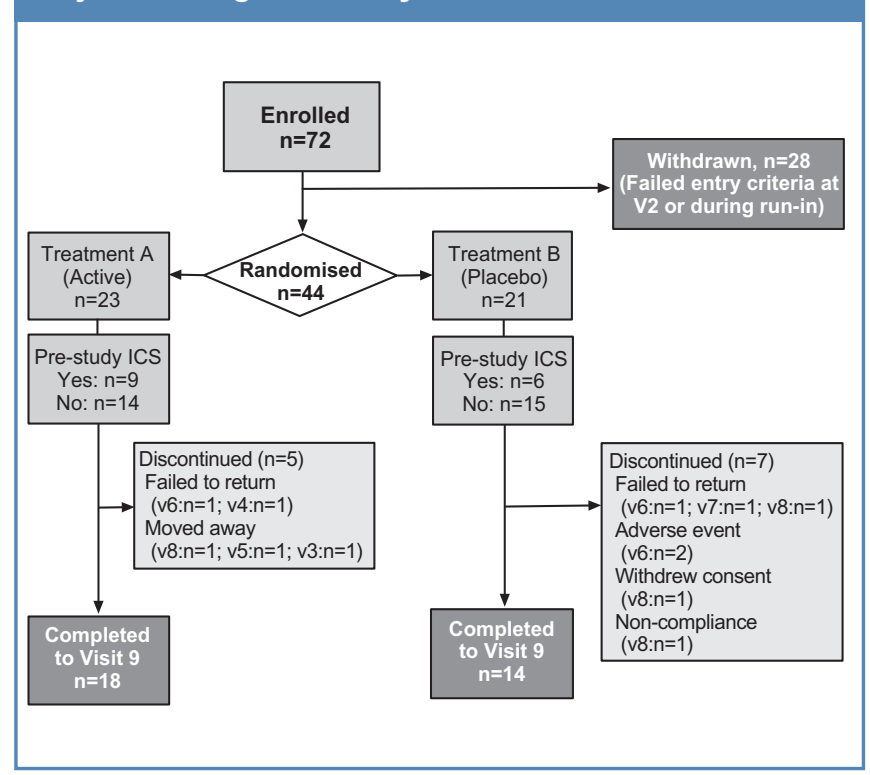




\section{AHEAD OF PRINT - ARTICLE IN PRESS}

HK Reddel et al.

Table 1. Demographic and baseline characteristics.

\begin{tabular}{|c|c|c|}
\hline & Active $(n=23)$ & Placebo $(n=21)$ \\
\hline Females, n (\%) & $13(57 \%)$ & $15(71 \%)$ \\
\hline Age, years, mean (range) & $37.3(19-68)$ & $41.4(20-73)$ \\
\hline \multicolumn{3}{|l|}{ Duration of asthma yrs, } \\
\hline Non-smoker/ex-smoker, n & $17 / 6$ & $16 / 5$ \\
\hline Atopic, n (\%) & $20(87 \%)$ & $19(90 \%)$ \\
\hline \multicolumn{3}{|l|}{ Clinic lung function } \\
\hline $\mathrm{FEV}_{1} \%$ predicted $^{1}$ & 96.6 (89.7-103.5) & $102.0(95.5-108.6)$ \\
\hline PEF \% predicted ${ }^{1}$ & $102.4(95.7-111.1)$ & $108.6(100.1-117.2)$ \\
\hline \multicolumn{3}{|l|}{ FeNO, ppb, geometric } \\
\hline mean $(95 \% \mathrm{CI})$ & $21.6(17.1-27.2)$ & $16.5(12.3-22.2)$ \\
\hline $\mathrm{DRR}, \% / \mu \mathrm{mol}^{2}$ & $10.96(3.00-23.52)$ & $5.67(1.62-18.66)$ \\
\hline AQLQ 2 & $0.40(0.15-0.70)$ & $0.25(0.10-0.50)$ \\
\hline \multicolumn{3}{|l|}{ Electronic Diary Data } \\
\hline Morning $\mathrm{FEV}_{1} \%$ predicted $^{1}$ & $87.1(80.7-93.5)$ & $89.7(83.0-96.4)$ \\
\hline Morning PEF \% predicted ${ }^{1}$ & $95.4(89.3-101.4)$ & $101.2(93.2-109.2)$ \\
\hline$\%$ Symptom-free days ${ }^{2}$ & $91.7(73.0-100.0)$ & $100.0(66.7-100.0)$ \\
\hline$\%$ Reliever-free days ${ }^{2}$ & $100(86.7-100.0)$ & $93.3(80.0-100.0)$ \\
\hline Reliever use, puffs/day ${ }^{2}$ & $0.0(0.0-0.14)$ & $0.1(0.0-0.18)$ \\
\hline
\end{tabular}

${ }^{1}$ Mean $\left(95 \%\right.$ confidence interval), ${ }^{2}$ M edian (IQR)

Atopic - defined as having one or more skin test responses with mean diameter $\geq 3 \mathrm{~mm}$ and greater than the negative control.

FeNO = exhaled nitric oxide, measured offline at $200 \mathrm{ml} / \mathrm{sec}$; upper limit of normal $13.2 \mathrm{ppb}^{23}$. DRR = Dose Response Ratio, calculated from histamine challenge as $\%$ fall in $\mathrm{FEV}_{1}$ divided by cumulative dose of histamine in $\mu \mathrm{mol}$, plus a constant of 3 . AQLQ $=$ Marks

asthma-related quality of life questionnaire ${ }^{20}$, range $0-4$ (best-worst).

\section{Secondary outcome variables (Table 2)}

For morning $\mathrm{FEV}_{1}$ and morning PEF expressed as percent predicted, treatment differences were 5.4 percentage points $(95 \% \mathrm{Cl} 4.3-6.4, p<0.0001)$ and 3.5 percentage points $(2.7-4.3, p<0.0001)$, respectively. Between-group differences increased during the course of the study $(p=0.0005$, Figure 2$)$. Significant treatment effects were also seen for evening $\mathrm{FEV}_{1}$ $\%$ predicted $(p=0.0001)$ and PEF \% predicted $(p=0.0001)$, and for clinic FEV $1(p=0.007), \operatorname{FVC}(p=0.02)$ and PEF $(p=0.01)$, each percent predicted. Median change in airway responsiveness was 1.24 doubling doses (IQR 0.42-2.07) for Active and 0.03 doubling doses $(-0.30-0.66)$ for Placebo ( $p=0.0025$ between groups). Likewise, there was a significant treatment effect on FeNO, with levels $37 \%$ lower in the Active vs the Placebo group ( $p=0.0001$ ).

There were no significant differences between Active and Placebo groups in morning or evening symptom scores, nightwaking, symptom-free days or reliever-free days. During treatment, a median of $92 \%$ days (IQR 83.7-96.5) were symptom-free for Active and 90\% (71.3-94.6) for Placebo Groups ( $p=0.07$ ), with median $94 \%$ and $91 \%$ days relieverfree for Active and Placebo respectively. Asthma-related Quality of Life (range 0-4, best-worst) was also not significantly different between Active and Placebo, with median scores of 0.275 and 0.375 respectively $(p=0.6)$.

There was a significant difference in the number of subjects with one or more mild exacerbations (Active - 5 $(22 \%)$ vs. Placebo - $13(62 \%), p=0.016)$. There was no significant difference in the number of subjects with severe exacerbations (two and three subjects respectively, $p=0.9$ ).

Average daily dose of fluticasone was median $250 \mathrm{mcg}$ (IQR 250-250) for Active group subjects (regular plus

Table 2. Effect of treatment on primary and secondary outcome variables.

\begin{tabular}{|c|c|c|c|c|c|}
\hline \multicolumn{6}{|c|}{ On treatment values ${ }^{1}$} \\
\hline & & Active & Placebo & Difference $(95 \% \mathrm{Cl})$ & $p$ value \\
\hline \multirow[t]{2}{*}{ Primary outcomes } & Morning PEF L/min & 459.7 & 443.8 & $15.93(12.44-19.42)^{2,3}$ & 0.0001 \\
\hline & Morning $\mathrm{FEV}_{1} \mathrm{~L}$ & 2.87 & 2.72 & $0.15(0.114-0.184)^{2,3}$ & 0.0001 \\
\hline \multirow[t]{6}{*}{ Secondary outcomes } & Morning PEF \% predicted & 101.60 & 98.06 & $3.54(2.70-4.34)^{2}$ & 0.0001 \\
\hline & M orning $\mathrm{FEV}_{1} \%$ predicted & 91.59 & 86.22 & $5.37(4.30-6.44)^{2}$ & 0.0001 \\
\hline & Clinic $\mathrm{FEV}_{1} \%$ predicted & 100.34 & 96.34 & $4.30(1.25-7.36)^{2}$ & 0.007 \\
\hline & FeNO, ppb & $12.30^{4}$ & $19.88^{4}$ & $0.63(0.52-0.75)^{5}$ & 0.0001 \\
\hline & Symptom-free days, \% & $92.0^{6}$ & $90.2^{6}$ & $1.09(0.99-1.18)^{7}$ & 0.07 \\
\hline & Reliever-free days, \% & $93.8^{6}$ & $91.3^{6}$ & $1.05(0.96-1.14)^{7}$ & 0.31 \\
\hline \multicolumn{6}{|c|}{ See text for airway hyperresponsiveness results. } \\
\hline \multicolumn{6}{|c|}{$\begin{array}{l}{ }^{1} \text { Least squares means adjusted for baseline, except where otherwise indicated; }{ }^{2} \text { Difference between active and placebo treatment; }{ }^{3} \text { Also adjusted for } \\
\text { age, gender and height; }{ }^{4} \text { Geometric mean values; }{ }^{5} \text { Ratio of FeNO in active group to FeNO in placebo group; }{ }^{6} \text { Median of post-randomisation period; } \\
{ }^{7} \text { Relative risk for symptom- or reliever-free day }\end{array}$} \\
\hline \multicolumn{6}{|c|}{ FeNO - exhaled nitric oxide, offline, flow rate $200 \mathrm{~mL} / \mathrm{sec}$, normal value $>13.2 \mathrm{ppb}^{23}$} \\
\hline
\end{tabular}


Figure 2. Morning FEV 1 percent predicted over 11 months of treatment.

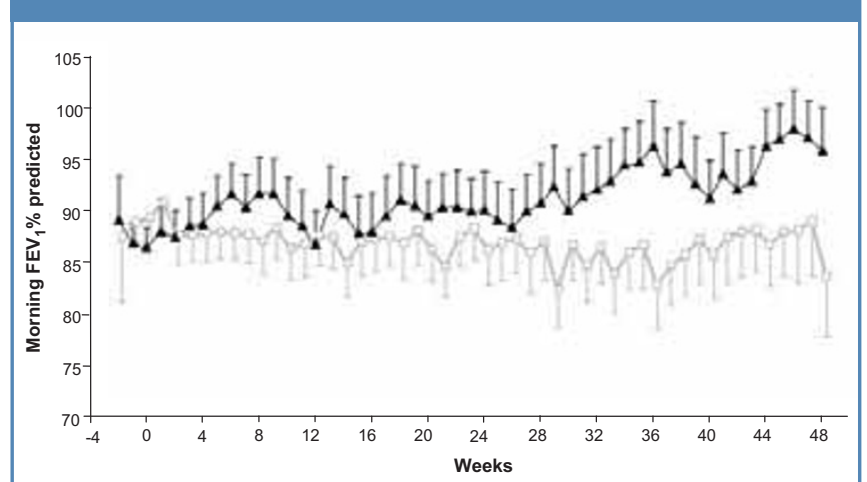

Solid triangles: fluticasone 125 mcg twice-daily, open squares: placebo. By mixed model ANOVA, there was a significant difference between active and placebo treatment (5.4 percentage points, $95 \% \mathrm{Cl} 4.3-6.4, p=0.0001)$. The effect of treatment increased with time ( $p=0.0005$, mixed model analysis). Morning $\mathrm{FEV}_{1}$ was obtained from daily electronic spirometric monitoring.

exacerbation treatment), and $44 \mathrm{mcg}(0-58)$ for Placebo group subjects (exacerbation treatment only), $p<0.0001$, Mann-Whitney U-test. Adverse events occurred at similar frequencies in both groups (see Appendix $A$ at www.thepcrj.org).

\section{Discussion}

This 11-month study demonstrated that in patients with mild or well controlled asthma, regular treatment with low dose inhaled fluticasone ( $250 \mathrm{mcg} / \mathrm{day})$ led to significantly better day-to-day lung function than did placebo. The double-blind placebo-controlled design, with the addition of four weeks of fluticasone in both groups for treatment of exacerbations, meant that the study mimicked the effect of continuous vs intermittent ICS. Subjects receiving placebo were nearly three times more likely to experience a mild exacerbation. There were also significant and clinically important treatment benefits on markers of future risk such as clinic lung function, airway hyperresponsiveness and exhaled nitric oxide, but no significant differences for symptoms, reliever use, night waking or asthma-related quality of life.

The main criterion for selection of subjects with "mild" asthma was that, at randomisation, they experienced symptoms and used $\beta_{2}$-agonist for two days/week or less. The possibility that low symptom-reporting may have been due to poor perception was anticipated by excluding subjects with moderate or severe airway hyperresponsiveness or excessive PEF variability. At baseline, for the study population as a whole, $\beta_{2}$-agonist use was reported less than weekly and $\mathrm{FEV}_{1}$ was $99 \%$ predicted, considerably milder features than in previous studies. ${ }^{15}$ However, $86 \%$ of subjects at entry had airway hyperresponsiveness and/or elevated FeNO. This indicates that there was underlying disease activity, including in those patients already taking ICS at entry. Confirmation of the diagnosis of asthma in patients with mild disease may be difficult, since the objective tests commonly used for this purpose in clinical trials are often only positive when asthma is poorly controlled or severe, In this study, if historical evidence of significant bronchodilator reversibility was not available, confirmation was sought from two physicians independently that the patient had a typical clinical history consistent with asthma.

The main limitation of the study is its small sample size. We have become accustomed to large sample sizes in studies powered on asthma exacerbations, but it is difficult to incorporate detailed pathophysiological markers into such studies. The study was appropriately powered for its primary outcome variable, demonstrating that, when repeated measures analysis and electronic monitoring are used, large sample sizes are not required in order to show clinically important and statistically significant differences in standard clinical measures of asthma control and disease activity.

The strengths of this study lie in the assessment of objective disease markers, the selection of a heterogeneous group of subjects with truly mild clinical manifestations of asthma, and the use of electronic diary spirometers. With real-time quality control, electronic monitoring provides highquality data ${ }^{24}$ about day-to-day asthma control (in this case, symptoms, reliever use and lung function), which are not adequately captured by interval questionnaires because of recall bias or by paper diaries because of poor adherence and data fabrication. Electronic diaries also reduce the burden of monitoring for patients, enhancing adherence, ${ }^{25}$ and increasing the number of data points, thus minimising the required sample size.

The primary outcome variables were daily morning PEF and morning $\mathrm{FEV}_{1}$, assessed over the whole treatment period. Despite near-normal lung function at entry, important and significant treatment differences were seen in morning and evening PEF and $\mathrm{FEV}_{1}$, around $16 \mathrm{~L} / \mathrm{min}$ for PEF and $150 \mathrm{~mL}$ for $F E V_{1}$. Papi and colleagues also found significant differences in morning and evening PEF in mild asthma treated with regular beclometasone $500 \mathrm{mcg} /$ day compared with placebo. ${ }^{26}$ These findings contrast with those of two other studies ${ }^{3,4}$ in mild persistent asthma, perhaps due to their use of lower ICS doses (200 mcg budesonide), and our use of continuous daily measurements over the whole treatment period. Both the present and previous studies ${ }^{3,4,6}$ showed a clinical benefit of low dose ICS on pre-bronchodilator clinic lung function. Markers of disease activity such as AHR and FeNO (used as a surrogate marker for eosinophilic airway inflammation) are not often measured in clinical trials, but the 
present study confirmed previous findings ${ }^{3}$ of significant improvement in these measures during ICS treatment. Similar effects on clinical, physiological and inflammatory markers have been seen with moderate-to-high dose ICS. ${ }^{7,8}$ However, the present study is the first to demonstrate these changes with low dose ICS in patients with such mild clinical manifestations of asthma. ${ }^{15}$

Not surprisingly, given that reliever use in the present study averaged less than weekly at baseline, we found no differences in symptoms, reliever use or quality of life between ICS and placebo. In a recent study, significant benefits were seen for symptoms and reliever use with regular low dose ICS vs placebo, but these patients at baseline had symptoms on about half of days. ${ }^{26}$ In very mild or well controlled asthma, symptom frequency and reliever use display genuine "floor" effects. However, the present study showed that a "ceiling" effect for lung function, which is sometimes assumed to prevail in mild asthma, does not exist because even patients whose lung function is near to $100 \%$ of the predicted normal value may have room to improve their personal best further with treatment.

These results highlight the difficulties in assessing priorities for treatment decisions in mild asthma. The goals of asthma treatment ${ }^{1}$ refer not only to relief and prevention of symptoms, but also to the prevention of exacerbations and decline in lung function, and avoidance of side effects of treatment. In patients with mild asthma, symptoms are infrequent, and may therefore carry little burden to patients, as indicated by the near-normal quality of life scores in this and other studies. ${ }^{3}$ However, at a population level, mild asthma is associated with substantial use of health care resources. ${ }^{27}$ Serious exacerbations do occur in patients with mild asthma, ${ }^{6,28}$ even if their baseline $\mathrm{FEV}_{1}$ is $>80 \%$ predicted, ${ }^{6}$ and severe exacerbations are significantly reduced by low dose ICS. ${ }^{4,6}$ Although large sample sizes and long-term studies are required for the formal study of severe exacerbations, features such as airway obstruction, airway hyperresponsiveness and airway inflammation are independent predictors of exacerbations, ${ }^{29-31}$ and can be used as surrogate measures for future risk. Changes in markers of disease activity cannot be ignored, because of their implications at a population level for the prediction of exacerbation risk. Likewise, low-dose ICS have been reported to reduce significantly long-term decline in lung function ${ }^{5}$ although this finding was not seen in another study, ${ }^{3}$ perhaps due to pretreatment with intense combined therapy, a treatment option which is not normally used in mild asthma.

Demonstration of the efficacy of low dose ICS in disease control and prevention of future risk in mild asthma may not translate to the widespread adoption of such treatment. Subjects in clinical trials may be more adherent with medication and monitoring than patients in clinical practice.
As in diabetes and hypertension, in which symptoms also relate poorly to long-term risks, patients with mild asthma may perceive regular treatment to be unnecessary because they have few symptoms, and because those that occur are readily relieved by $\beta_{2}$-agonist treatment. In addition, although low dose ICS have few observed risks, ${ }^{32}$ they carry a significant burden of perceived side-effects, ${ }^{33,34}$ and of cost to the patient and the economy. ${ }^{9}$ For some patients, the risk and cost of regular treatment will be unacceptable, and treatment will continue to be taken on an intermittent basis. In this study, the use of fluticasone only for four weeks after exacerbations reduced the total daily fluticasone dose (averaged for each patient over 11 months) from 250 $\mathrm{mcg} / \mathrm{day}$ to $44 \mathrm{mcg} / \mathrm{day}$. Although asthma outcomes were worse in subjects randomised to regular placebo, intermittent ICS treatment may be better than no treatment. Papi and colleagues $^{26}$ have shown that combination low dose ICS/salbutamol, used as-needed for symptoms, provides similar benefits to those obtained with regular twice-daily ICS, with a much lower ICS dose. However, similar effects could not be assumed to occur if ICS alone was used as-needed, without immediate symptom relief to encourage patient use of the inhaler. Studies with electronic monitoring of adherence are urgently needed to characterise the relationship between actual medication behaviour and clinical outcomes.

in summary, this study recruited patients with very mild clinical manifestations of asthma, the majority of whom would not normally receive regular ICS. We found significant and clinically important differences between treatment with low dose ICS and placebo in lung function and mild exacerbations, and in markers of underlying disease activity, which have been demonstrated to predict future risk to patients. The low rate of symptoms and reliever use at entry suggests that patient-centred features may not provide all of the information that clinicians need in order to consider whether patients with mild asthma would benefit from ICS treatment. For such patients, discussion about low dose ICS as a treatment option needs to encompass not only shortterm benefit, side effects and cost, but also long-term reduction of risk.

\section{Conflict of interest and acknowledgements}

The authors gratefully acknowledge the valuable contribution of Jessica DameCarroll, Sharon Wilson, Susan Forest-Blythe and Tessa Bird for data collection. The assistance of Dr Cheryl Salome regarding FeNO monitoring and Dr Wei Xuan in statistical analysis is appreciated.

This study was initiated by the investigators. It was funded by the Woolcock Institute of Medical Research and GlaxoSmithKline Australia. GlaxoSmithKline Australia (Boronia, Victoria, Australia) provided and packaged the study medications and exacerbation medication, and provided Volumatic spacers, but had no role in the analysis or interpretation of the results or in the writing or editing of this manuscript. HKR was supported by the Asthma Foundation of NSW, Cooperative Research Centre for Asthma and University of Sydney. 


\section{References}

1. Global Initiative for Asthma. Global strategy for asthma management and prevention. 2006 [cited August 2007]; Available from: www.ginasthma.com

2. National Heart Lung and Blood Institute National Asthma Education and Prevention Program. Expert Panel Report 3: Guidelines for the Diagnosis and Management of Asthma. 2007 August 2007 [cited 2007 September 2007]; Available from: http://www.nhlbi.nih.gov/guidelines/asthma/asthgdln.htm

3. Boushey HA, Sorkness CA, King TS, et al. Daily versus as-needed corticosteroids for mild persistent asthma. N Engl J M ed 2005;352:1519-28.

4. O'Byrne PM, Barnes PJ, Rodriguez-Roisin R, et al. Low dose inhaled budesonide and formoterol in mild persistent asthma: the OPTIMA randomized trial. Am J Resp Crit Care Med 2001;164:1392-7.

5. O'Byrne PM, Pedersen S, Busse WW, et al. Effects of early intervention with inhaled budesonide on lung function in newly diagnosed asthma. Chest 2006;129:1478-85.

6. Pauwels RA, Pedersen S, Busse WW, et al. Early intervention with budesonide in mild persistent asthma: a randomised, double-blind trial. Lancet 2003;361:1071-6.

7. Laitinen LA, Laitinen A, Haahtela T. A comparative study of the effects of an inhaled corticosteroid, budesonide, and a $\beta 2$-agonist, terbutaline, on airway inflammation in newly diagnosed asthma: A randomized, double-blind, parallel-group controlled trial. J Allergy Clin Immunol 1992;90:32-42.

8. Lim S, Jatakanon A, John M, et al. Effect of inhaled budesonide on lung function and airway inflammation. Assessment by various inflammatory markers in mild asthma. Am J Respir Crit Care M ed 1999;159:22-30.

9. Boushey HA. Daily inhaled corticosteroid treatment should not be prescribed for mild persistent asthma. Am J Resp Crit Care Med 2005;172:412-14.

10. Fabbri LM. Does mild persistent asthma require regular treatment? N Engl J Med 2005;352:1589-91.

11. Fabbri LM, Stoloff S. Is mild asthma really 'mild'? Int J Clin Pract 2005;59:692703.

12. Irani AM. The challenge of mild persistent asthma. Ann Allergy Asthma Immunol 2005;94:517-27.

13. Lazarus SC. Mild persistent asthma: is any treatment needed? J Allergy Clin Immunol 2006;118:805-08.

14. O'Byrne PM. Daily inhaled corticosteroid treatment should be prescribed for mild persistent asthma. Am J Resp Crit Care Med 2005;172:410-12.

15. O'Byrne PM, Parameswaran K. Pharmacological management of mild or moderate persistent asthma. Lancet 2006;368:794-803.

16. Kraft M, Israel E, O'Connor GT. Clinical Decisions. Treatment of mild persistent asthma. N Engl J Med 2007;356:2096-100.

17. Rytila P, Metso T, Heikkinen K, et al. Airway inflammation in patients with symptoms suggesting asthma but with normal lung function. Eur Respir J
2000;16:824-30.

18. Jatakanon A, Lim S, Kharitonov SA, Chung KF, Barnes PJ. Correlation between exhaled nitric oxide, sputum eosinophils, and methacholine responsiveness in patients with mild asthma. Thorax 1998;53:91-5.

19. Reddel HK, Salome CM, Peat JK, Woolcock AJ. Which index of peak expiratory flow is most useful in the management of stable asthma? Am J Resp Crit Care Med 1995;151:1320-5.

20. Marks GB, Dunn SM, Woolcock AJ. A scale for the measurement of quality of life in adults with asthma. J Clin Epidemiol 1992;45:461-72.

21. Yan K, Salome CM, Woolcock AJ. Rapid method for measurement of bronchial responsiveness. Thorax 1983;38:760-5.

22. Reddel HK, Jenkins CR, M arks GB, et al. Optimal asthma control, starting with high doses of inhaled budesonide.[erratum in Eur Respir J 2000;16:579]. Eur Respir J 2000;16:226-35.

23. Deykin A, Massaro AF, Drazen JM, Israel E. Exhaled nitric oxide as a diagnostic test for asthma: online versus offline techniques and effect of flow rate. Am J Resp Crit Care Med 2002;165:1597-601.

24. Reddel HK, Ware SI, Salome CM, Jenkins CR, Woolcock AJ. Pitfalls in processing home electronic spirometric data in asthma. Eur Respir J 1998; 12:853-8.

25. Slader CA, Belousova EG, Reddel HK. Measuring peak flow enhances adherence to monitoring in asthma. Thorax 2007; 62:741-2.

26. Papi A, Canonica GW, Maestrelli P, et al. Rescue use of beclomethasone and albuterol in a single inhaler for mild asthma. N Engl J Med 2007;356:2040-52.

27. Chapman KR. Impact of 'mild' asthma on health outcomes: findings of a systematic search of the literature. Respir M ed 2005;99:1350-62.

28. Fuhlbrigge AL, Adams RJ, Guilbert TW, et al. The burden of asthma in the United States: level and distribution are dependent on interpretation of the national asthma education and prevention program guidelines. Am J Resp Crit Care Med 2002;166:1044-9.

29. Jatakanon A, Lim S, Barnes PJ. Changes in sputum eosinophils predict loss of asthma control. Am J Resp Crit Care Med 2000;161:64-72.

30. Kitch $B T$, Paltiel $A D$, Kuntz $K M$, et al. A single measure of FEV1 is associated with risk of asthma attacks in long-term follow-up. Chest 2004;126:1875-82.

31. Leuppi JD, Salome CM, Jenkins CR, et al. Predictive markers of asthma exacerbation during stepwise dose reduction of inhaled corticosteroids. Am J Resp Crit Care Med 2001;163:406-12.

32. Powell H, Gibson PG. Inhaled corticosteroid doses in asthma: an evidencebased approach. Med J Aust 2003;178:223-5.

33. Boulet LP. Perception of the role and potential side effects of inhaled corticosteroids among asthmatic patients. Chest 1998;113:587-92.

34. Ulrik C, Backer V, Soes-Petersen U, et al. The Patient's Perspective: Adherence or Non-adherence to Asthma Controller Therapy? J Asthma 2006;43:701-04.

Available online at http://w w w.thepcrj.org 


\section{Online supplement}

A secondary hypothesis for this study was that patients who ceased taking regular ICS, and took them only during exacerbations, would develop more symptoms, poorer lung function and other clinical features of poor asthma control compared with patients who continued to take inhaled corticosteroids over the same period.

In order to test this hypothesis, it was planned to examine the effect of pre-randomisation use of ICS on the effect of treatment on outcome variables, using an interaction term, prior to the analyses described in the main paper. If this analysis was significant $(p<0.05)$, subsequent analyses were to be performed separately by the two subgroups (ICS use/non-use prior to entry). For this purpose, the main fixed effects were treatment group, sub-group, and baseline variable, and the interaction tested was treatment group by subgroup. The coefficient and standard error for the treatment group by subgroup interaction was used to test and estimate the difference in treatment efficacy between the subgroups. These analyses were specified prior to database lock.

\section{Results of subgroup analysis}

Subgroup analysis for the effect of ICS use prior to entry was carried out as planned. Fifteen subjects were using ICS prior to entry ( 9 active, 6 placebo), and 29 were not (14 active, 15 placebo). There was a greater treatment effect for morning PEF in subjects using ICS at entry (31.3 [24.0-38.7] cf. 9.4 [5.3-13.6] L/min) but the effect of ICS treatment vs placebo was significant for both subgroups $(p<0.0001$ and $p<0.0006$ respectively). There was no significant interaction with ICS use at entry for morning $\mathrm{FEV}_{1}$. For clinic lung function, the treatment effect for PEF \% predicted was seen only in the subjects who were using ICS at entry $(11.4 \%$ [6.5-16.3, $p=0.0003]$ cf. $2.5 \%$ [-2.7-7.8, $p=0.33]$ ), but the interaction for $\mathrm{FEV}_{1} \%$ predicted was not significant $(p=0.24)$. There was no significant interaction between previous ICS use and the treatment effect on FeNO $(p=0.7)$.

\section{Interpretation of subgroup analysis}

The number of subjects in each subgroup was small, so the results need to be interpreted with caution. The greater treatment effect which was seen for morning PEF and clinic PEF in subjects who were taking ICS at entry initially appears counter-intuitive, as one would expect less room for improvement in those already taking ICS. Without electronic recording of ICS use, it is not possible to be certain that subjects who were previously prescribed ICS had actually been taking this medication prior to entry, so their subsequent improvement on active treatment may have reflected improved adherence during the clinical trial. However, examination of the results indicated that there were no significant differences in baseline AHR or FeNO between those using/not using ICS at entry, and the difference in subgroup analysis was largely due to a greater deterioration in those previously on ICS who were randomised to placebo. In addition, the stratification of subjects into those taking or not taking ICS at entry was based not on whether they had been prescribed ICS but on their self-reported ICS use. In many cases subjects reported poor or zero adherence with previous prescriptions, information which (unlike selfreported good adherence) is likely to be reliable. ${ }^{1} \mathrm{~A}$ more likely explanation for the greater effect of regular fluticasone treatment in subjects who had been taking ICS prior to entry is that these subjects may have self-selected for ICS use prior to entry on the basis of a previous experience of deterioration when they stopped taking ICS.

The fact that there was a significant difference in the subanalysis for $P E F$ and not for $F E_{1}$ is not explained, but we have previously noted greater ICS treatment effects on PEF than on $\mathrm{FEV}_{1}$, when the PEF data were collected electronically from spirometric manoeuvres. ${ }^{2}$ Examination of baseline clinic lung function showed that although PEF \% predicted was somewhat higher in those previously receiving ICS (112.0 cf. $102.7 \%$ predicted, $p=0.11$ ), there was no difference in $\mathrm{FEV}_{1}$ $\%$ predicted (101.2 cf $98.2 \%$ predicted, $p=0.5$ ), suggesting some mild mid-expiratory flow obstruction in the group previously receiving ICS. This may have occurred by chance, given the small numbers, or may have been related to previous treatment.

\section{Adverse events}

Adverse events occurred at a similar frequency in both groups, with the most common reported episodes being respiratory tract infections (active: 18 subjects; placebo: 13 subjects). Fourteen subjects reported mouth/throat pain or irritation (active: 7, placebo: 7), 4 reported dysphonia (active: 3, placebo: 1), and one reported easy bruising (placebo). Two subjects in the placebo group discontinued because of adverse events (one with three asthma exacerbations, one for bronchitis).

\section{References}

1. Rand CS, Nides M, Cowles MK, W ise RA, Connett J, for the Lung Health Study Research Group. Long-term metered-dose inhaler adherence in a clinical trial. Am J Resp Crit Care Med 1995;152:580-8.

2. Reddel HK, Jenkins CR, M arks GB, Ware SI, Xuan W, Salome CM, Badcock CA, and Woolcock AJ. Optimal asthma control, starting with high doses of inhaled budesonide. Eur Respir J 2000;16:226-35 [erratum in Eur Respir J 2000; 16:579]. 